\title{
MAKSIMALKAN PRODUKTIVITAS TANAMAN PADI DENGAN PUPUK SUBSIDI YANG SEDIKIT
}

\author{
Widodo \\ Balai Penyuluhan Pertanian (BPP) Sunan kalijaga Kecamatan Sambungmacan \\ Alamat : Jalan Raya Timur KM 13, Sambungmacan, 57253
}

\begin{abstract}
Increased productivity of rice crops is the target of all farmers, one of the ways taken is to increase the dose of chemical fertilizer (an organic) is excessive. The dose of chemical fertilizers is currently limited by the quota of the government, to meet the needs of fertilizer farmers willing to buy from anywhere and at whatever price from the needs of adequate fertilizer. What farmers do is true but farmers do not understand that the way they do fertilization is less precise, the way fertilization directly result in the amount of fertilizer is lost free, this is because the fertilizer is lost to evaporate or participate in water soluble without exploited by the plant, as For example if we cultivate 3 sak of chemical fertilizers utilized by plants only 1 sak only, so only $30-40 \%$ are used by plants while $60-70 \%$ is lost in vain. There is one thought that how to fertilize the right so that $60-70 \%$ can dipfatkan plants so that farmers do not have to increase the dose of fertilization because this is contrary to the quota of fertilizer from the government a little. We held a trial in the form of demplot selam 5 seasons that is by doing chemical fertilizer curing according to government quota but we add a binder media that is organic fertilizer. We do curing for 5-7 days before application. From the results of our demonstration plots give very significant results the condition of the plant is physically grown with normal and productivity / yield is not inferior to the treatment of farmers who use chemical fertilizers excess.
\end{abstract}

Keywords: Maximize yield, Grounding, Organic Fertilizer.

\section{ABSTRAK}

Peningkatan produktivitas tanaman padi menjadi target semua petani, salah satu cara yang ditempuh yaitu dengan menambah dosis pupuk kimia (an organik) yang berlebih. Dosis pupuk kimia pada saat ini dibatasi sesuai kuota dari pemerintah, untuk mencukupi kebutuhan pupuk petani rela membeli dari manapun dan dengan harga berapapun asal kebutuhan pupuk tercukupi. Yang dilakukan petani memang benar namun petani belum memahami bahwa cara pemupukan yang mereka lakukan kurang tepat, cara pemupukan secara langsung berakibat pada banyaknya kandungan pupuk yang hilang percuma, hal ini disebabkan karena pupuk tersebut hilang menguap atau ikut larut dalam air tanpa dimanfaatkan oleh tanaman, sebagai contoh apabila kita memupuk 3 sak pupuk kimia yang dimanfaatkan oleh tanaman hanya 1 sak saja, jadi hanya $30-40 \%$ yang dimanfaatkan tanaman sedangkan $60-70 \%$ hilang sia-sia. Timbul satu pemikiran bahwa bagaimana cara pemupukan yang tepat agar $60-70 \%$ bisa dimanfatkan tanaman sehingga petani tidak harus menambah dosis pemupukan karena hal ini bertentangan sekali dengan kuota pupuk dari pemerintah yang sedikit. Kami mengadakan uji coba dalam bentuk demplot selam 5 musim tanam yaitu dengan cara melakukan pemeraman pupuk kimia sesuai kuota pemerintah namun kami menambahkan media pengikat yaitu pupuk organik. Kami lakukan pemeraman selama 5-7 hari sebelum aplikasi. Dari 
hasil demplot yang kami lakukan memberikan hasil yang sangat signifikan kondisi tanaman secara fisik tumbuh dengan normal dan produktivitas/hasil tidak kalah dengan perlakuan petani yang menggunakan pupuk kimia berlebih.

Kata Kunci : Maksimalkan hasil, Pemeraman, Pupuk Organik.

\section{Pendahuluan}

Padi merupakan salah satu komoditas strategis baik secara ekonomi, sosial maupun politik. Komoditas padi juga merupakan komponen utama dalam sistem ketahanan pangan nasional. Oleh karena itu, masalah padi dan perberasan akan tetap menjadi sektor pertanian yang sangat strategis secara ekonomi, sosial dan politik (Pinem, 2007). Kebutuhan beras sebagai salah satu sumber pangan utama penduduk Indonesia akan terus meningkat seiring pertambahan penduduk dengan peningkatan $1,36 \%$ per tahun

Hampir semua aktivitas pertanian atau perkebunan pasti melakukan kegiatan pemupukan. Dampak dari kegiatan pemupukan diharapkan mampu meningkatkan hasil pertanian atau perkebunan. Sehingga nantinya mampu memberikan hasil yang optimal dan memberikan keuntungan dari segi ekonomi.

Pada umumnya tanaman tidak bisa menyerap 100\% pupuk kimia. Selalu akan ada residua atau sisanya. Sisa-sisa pupuk kimia yang tertinggal di dalam tanah ini, bila telah terkena air akan mengikat tanah seperti lem/semen. Setelah kering, tanah akan lengket satu dengan lain (alias tidak gembur lagi), dan keras. Selain keras, tanah juga menjadi masam. Kondisi ini membuat organisme-organisme pembentuk unsur hara (organisme penyubur tanah) menjadi mati atau berkurang populasinya. Beberapa binatang yang menggemburkan tanah seperti cacing tidak mampu hidup di kawasan tersebut dan kehilangan unsur alamiahnya. Bila ini terjadi, maka tanah tidak bisa menyediakan makanan secara mandiri lagi, dan akhirnya menjadi sangat tergantung pada pupuk tambahan, khususnya pupuk kimia.

Prihatin dengan penggunaan pupuk anorganik (Kimia) yang dilakukan oleh petani pada tanaman padi yang semakin lama semakin banyak atau melebihi dosis. Kondisi tanaman kurang memuaskan bila dipupuk sedikit sehingga petani selalu menambah dosis pupuk kimia agar hasil tanaman padi meningkat.

Timbul satu pertanyaan bagaimana agar pemupukan bisa optimal, kandungan unsur hara $50 \%$ yang hilang tersebut bisa kita minimalisir atau ditekan sehingga tanaman bisa tumbuh dengan baik sesuai dengan harapan petani produktivitas meningkat, terlebih lagi saat ini kuota atau jumlah pupuk bersubsidi semakin lama semakin dikurangi sehingga ini menjadi permasalahan yang dihadapi petani dikabupaten sragen bahkan se indonesia.

Saya mencoba melakukan percobaan selama 5 Musim Tanam yaitu dengan cara yang sangat sederhana yaitu dengan melakukan pemeraman terlebih dahulu 
pada semua pupuk yang akan diberikan pada tanaman padi dengan menambahkan pupuk organik (bebas bisa pabrikan atau produksi sendiri) dengan jumlah sama dengan pupuk an organik atau kimia yang dipakai petani.

Pemeraman bersamaan dengan pupuk organik ini dilakukan karena pupuk organik adalah sebagai media pengikat unsur kimia yang menguap sehingga kandungan unsur kimia yang menguap bisa ditekan dan bisa dimanfaatkan tanaman secara optimal tanpa harus menambah dosis pupuk.

Adapun uji coba secara swadaya ini saya lakukan sejak Bulan Oktober 2015 sampai dengan sekarang yaitu :

1. Musim Tanam 1 2015/2016

2. Musim Tanam 22016

3. Musim Tanam 12016

4. Musim Tanam $12016 / 2017$

5. Musim Tanam 22017

Dari hasil percobaan cara pemupukan yang saya lakukan ternyata mampu memberikan hasil yang memuaskan, secara fisik tanaman normal, sehat dan produktivitas tidak kalah dengan petani yang menggunakan pupuk yang lebih banyak bahkan cenderung lebih baik.

\section{RUMUSAN MASALAH}

Teori pemupukan sekitar 50\% yang diserap oleh tanaman, sedangkan 50\% hilang menguap dan larut dalam air tanpa dimanfaatkan oleh tanaman maka timbul ide untuk kandungan unsur hara $50 \%$ yang hilang tersebut bisa kita minimalisir atau ditekan sehingga tanaman bisa tumbuh dengan baik sesuai dengan harapan petani, produktivitas meningkat, terlebih lagi saat ini kuota atau jumlah pupuk bersubsidi semakin lama semakin dikurangi sehingga ini menjadi permasalahan yang dihadapi petani dikabupaten sragen bahkan se indonesia.

Dengan hilangnya 50\% pupuk tersebut Petani sudah tepat dengan menambah dosis pemupukan sehingga kebutuhan unsur hara tanaman terpenuhi, namun yang jadi masalah adalah kuota pupuk per luasan setiap tahun berkurang sehingga timbul satu masalah dari mana pupuk itu diperoleh

\section{HIPOTESIS KAJIAN}

Dengan cara pemeraman semua pupuk maka akan terjadi percampuran antara pupuk an organik dengan pupuk organik. Pupuk organik berfungsi sebagai media membantu mengikat unsur kimia pada pupuk an organik sehingga pupuk organik yang minim unsur kimia akan memiliki unsur kimia yang lebih tinggi 


\section{TINJAUAN PUSTAKA}

Pangan merupakan kebutuhan dasar bagi manusia memerlukannya menjadi Hak Asasi setiap warga masyarakat Indonesia guna mewujudkan Sumber Daya Manusia yang berkualitas untuk melaksanakan Pembangunan Nasional dalam struktur Pangan Nasional, Beras merupakan salah satu komoditas paling strategis dan merupakan hal yang paling banyak dikomsumsi masyarakat Indonesia. Oleh karena itu ketersediaan beras harus dijamin oleh pemerintah setiap saat untuk kestabilan ekonomi sosial dan keamanan

Kebutuhan beras sebagai salah satu sumber pangan utama penduduk Indonesia terus meningkat, karena selain penduduk terus bertambah dengan laju peningkatan sekitar $2 \%$ per tahun, juga adanya perubahan pola konsumsi penduduk dari non beras ke beras. Pada pihak lain terjadinya penciutan lahan saah irigasi subur (intensif) akibat konversi lahan untuk kepentingan non pertanian dan muncul fenomena degradasi kesuburan lahan menyebabkan produktivitas padi sawah irigasi cenderung melandai.

Hampir semua aktivitas pertanian atau perkebunan pasti melakukan kegiatan pemupukan. Dampak dari kegiatan pemupukan diharapkan mampu meningkatkan hasil pertanian atau perkebunan. Sehingga nantinya mampu memberikan hasil yang optimal dan memberikan keuntungan dari segi ekonomi.

Pupuk adalah zat, baik sistetis atau organik, yang ditambahkan ke tanah untuk meningkatkan pasokan nutrisi penting yang meningkatkan pertumbuhan tanaman dan vegetasi di dalam tanah. Meski ditujukan untuk memberikan keuntungan bagi manusia, namun dampak dari kegiatan pemupukan pada tanah perlu diperhatikan. Hal ini khususnya pada penggunaan pupuk kimia. Jika dilakukan secara berlebihan, penggunaan pupuk kimia bisa menimbulkan dampak yang justru merusak kesuburan tanah itu sendiri dan bukan menjadikannya subur. Pupuk kimia adalah pupuk yang dibuat oleh pabrik-pabrik pupuk dengan meramu bahan-bahan kimia anorganik berkadar hara tinggi.

Menurut riset para ahli, pada umumnya tanaman tidak bisa menyerap $100 \%$ pupuk kimia. Selalu akan ada residua atau sisanya. Sisa-sisa pupuk kimia yang tertinggal di dalam tanah ini, bila telah terkena air akan mengikat tanah seperti lem/semen. Setelah kering, tanah akan lengket satu dengan lain (alias tidak gembur lagi), dan keras. Selain keras, tanah juga menjadi masam. Kondisi ini membuat organisme-organisme pembentuk unsur hara (organisme penyubur tanah) menjadi mati atau berkurang populasinya. Beberapa binatang yang menggemburkan tanah seperti cacing tidak mampu hidup di kawasan tersebut dan kehilangan unsur alamiahnya. Bila ini terjadi, maka tanah tidak bisa menyediakan makanan secara 
mandiri lagi, dan akhirnya menjadi sangat tergantung pada pupuk tambahan, khususnya pupuk kimia.

Dekan Fakultas Pertanian Unsil Tasikmalaya Ida Hodiyah menegaskan, jika pupuk urea yang digunakan para petani $50 \%$ di antaranya sebenarnya terbuang percuma.

Pasalnya sisa dari pupuk yang menguap dan larut bersama air kemudian mencemari dan merusak lingkungan serta tanah yang menjadi media tanam para petani sendiri. "Penggunaan logam berat dalam kandungan urea ini sebagai salah satu penyebab kerusakan lingkungan, sebab kandungan kimiawinya bisa larut dalam air yang akan digunakan masyarakat.

\section{METODE KAJIAN}

Pengkajian dilaksanakan melalui kegiatan unit percontohan (Demplot) budidaya padi dengan menggunakan pupuk yang yang diperam bersama pupuk organik. Adapun dosis pupuk sesuai dengan Kuota Pupuk Bersubsidi dengan ditambah pupuk organik dalam Tabel Pemupukan.

Kegiatan Demplot/pengkajian dilaksanakan di Kecamatan Sambungmacan pada Musim Tanam :

1. Musim Tanam $12015 / 2016$

2. Musim Tanam 22016

3. Musim Tanam 12016

4. Musim Tanam 1 2016/2017

5. Musim Tanam 22017

Dalam budidaya padi kegiatan Demplot tersebut juga diterapkan beberapa komponen teknologi Pengelolaan Tanaman Terpadu (PTT) yaitu meliputi varietas unggul baru (Ciherang, Mekongga, MSP) perlakuan benih, sebar benih dengan tingkat kerapatan dan luas persemaian yang tepat, tanam bibit muda umur 15 hari, tanam 2-3 bbit per lubang tanam, tanam sistem jajar legowo $2: 1$, dan pengendalian OPT secara terpadu dan panen tepat waktu. 
Tabel Jumlah Pupuk sesuai dengan kondisi di Lapangan

\begin{tabular}{|c|c|c|c|}
\hline \hline Jenis Pupuk & $\begin{array}{c}\text { I } \\
\text { Kuota }\end{array}$ & $\begin{array}{c}\text { II } \\
\text { Perlakuan Petani }\end{array}$ & $\begin{array}{c}\text { III } \\
\text { Demplot }\end{array}$ \\
\hline UREA & 81 & 50 & 50 \\
\hline ZA & 25 & 50 & 50 \\
\hline SP36 & 18 & 100 & - \\
\hline PHONSKA & 53 & 100 & 50 \\
\hline ORGANIK & 32 & 80 & $\mathbf{2 0 0}$ \\
\hline KCL & - & 50 & - \\
\hline \hline JUMLAH & 209 & 430 & 350 \\
\hline \hline
\end{tabular}

Kolom 1 : Jumlah Kuota Pupuk yang tersedia

Kolom 2 : Jumlah Pemupukan yang lakukan Petani

Petani harus membeli pupuk dari luar walau harga tinggi

Kolom 3 : Demplot Pemupukan dengan cara diperam terlebih dahulu

Demplot Pemupukan dengan cara diperam yaitu : Mencampur terlebih dahulu semua pupuk An organi dan Organik (Urea, ZA, Phonska, KCL, Petroganik)

dan disimpan $5-7$ hari dengan kondisi tertutup. Lama penyimpanan minimal 5 hari sebelum di Tabur.

Kegiatan pemeraman ini dapat dilakukan sebelum kegiatan tanam padi atau setelah tanam padi, tergantung kesiapan petani tersebut.

Adapun proses dan cara kerja pemeraman pupuk yang dilakukan sebagai berikut :

Menyiapkan alat : Terpal untuk alas, Cangkul

Bahan :

1. Urea $: 50 \mathrm{~kg}$

2. ZA : $: 50 \mathrm{~kg}$

3. NPK Phonska : $50 \mathrm{~kg}$

4. Petroganik : $200 \mathrm{~kg}$

Jumlah $\quad: 350 \mathrm{~kg}$

Campur semua bahan secara merata kemudian tutup rapat dengan terpal dan diamkan selama 7-20 hari.

Aplikasi Pemupukan dilakukan 2 kali yaitu :

1. Aplikasi I : 7 HST (hari setelah tanam)

$175 \mathrm{~kg}$ campuran pupuk yang sudah diperam

2. Aplikasi II : 20 HST

175

kg campuran pupuk yang sudah diperam 


\section{HASIL DAN PEMBAHASAN}

Dari hasil demplot cara pemupukan diperam dapat kami laporkan sebagai berikut : dengan penggunaan pupuk an organik yang sedikit sesuai kuota pemerintah dan ditambah petroganik sebagai media pengikat unsur kimia maka hasil demplot yang dilakukan memberikan hasil yang cukup signifikan dibandingkan perlakuan petani, adapun hasil demplot yang kami lakukan sebagai berikut :

Tabel Hasil Ubinan 2,5 x 2,5 m pada petak kontrol (Perlakuan Petani) \& Demplot

\begin{tabular}{|c|c|c|c|c|}
\hline \multirow[b]{2}{*}{ No } & \multirow[b]{2}{*}{ Musim Tanam } & \multicolumn{2}{|c|}{ Ubinan 2,5 × 2,5 m (kw/ha) } & \multirow[b]{2}{*}{ Ket } \\
\hline & & $\begin{array}{c}\text { Perlakuan } \\
\text { Petani }\end{array}$ & Demplot & \\
\hline 1 & Musim Tanam 1 2015/2016 & 72,0 & 89,6 & \\
\hline 2 & Musim Tanam 22016 & 62,4 & 78,4 & \\
\hline 3 & Musim Tanam 12016 & 75,2 & 84,8 & \\
\hline 4 & Musim Tanam 1 2016/2017 & 78,4 & 92,8 & \\
\hline 5 & Musim Tanam 22017 & 68,8 & 75,2 & \\
\hline
\end{tabular}

Hasil ubinan di 5 musim tanam menunjukkan demplot yang dilakukan menunjukkan hasil yang lebih baik dibandingkan perlakuan petani.

\section{PENUTUP}

\subsection{Kesimpulan}

Masyarakat tani pada saat ini sangat bingung dengan kondisi pupuk yang kuotanya dibatasi sehingga untuk target peningkatan hasil menjadi terkendala. Namun petani tetap berusaha mencari sampai dapat walaupun harus beli dengan harga yang relatif tinggi.

Dengan adanya bukti hasil demplot yang signifikan maka perlu ada sosialisasi pada petani agar mencoba cara pemupukan yang cukup sederhana tanpa harus bingung menambah jumlah pupuk an organik tersebut.

Kemudian cara pemupukan ini sangat sederhana sekali namun membutuhkan media atau bahan pengikat unsur kimia yang berupa pupuk organik/petroganik sehingga memberikan peluang usaha bagi produsen pupuk organik untuk meningkatkan produksinya.

Dari hasil uji coba atau demplot dapat kami ambil kesimpulan :

1. Tanaman tumbuh dengan baik secara fisik Normal, Sehat \& Provitas tidak Kalah dengan perlakuan petani 
2. Produktivitas Meningkat

3. Bisa menjadi alternatif solusi kuota pupuk yang sedikit

4. Memberi Peluang bagi produsen Pupuk organik (Kelompok Tani maupun Perusahaan besar) untuk meningkatkan produksi pupuk organik

\subsection{Saran}

Namun dari hasil demplot ini tentu perlu di kembangkan lebih lanjut : Perlu ada Demplot Lanjutan Karena :

1. Belum mengetahui secara pasti berapa lama fermentasi yang baik

2. Belum mengetahui secara pasti Dosis Pupuk Organik sebagai media pengikat \& Pupuk An organik (Kimia)

\section{DAFTAR PUSTAKA}

http://koran-sindo.com/page/news/2017-05-14/4/41/50 Pupuk Urea Terbuang Percuma

http://m.tabloidsinartani.com/index.php?id=148\&tx ttnews[tt news] $=4504 \&$ cHash $=$ 29af594509b2ef924fe25836f7165801

http://www.kompasiana.com/charismarahma/masih-mau-pakai-pupuk-kimia-yukintip-bahayanya_54f84872a33311dd55e8b4963

50\% Pupuk Urea Terbuang Percuma 


\section{LAMPIRAN}

\section{Dokumentasi Demplot}

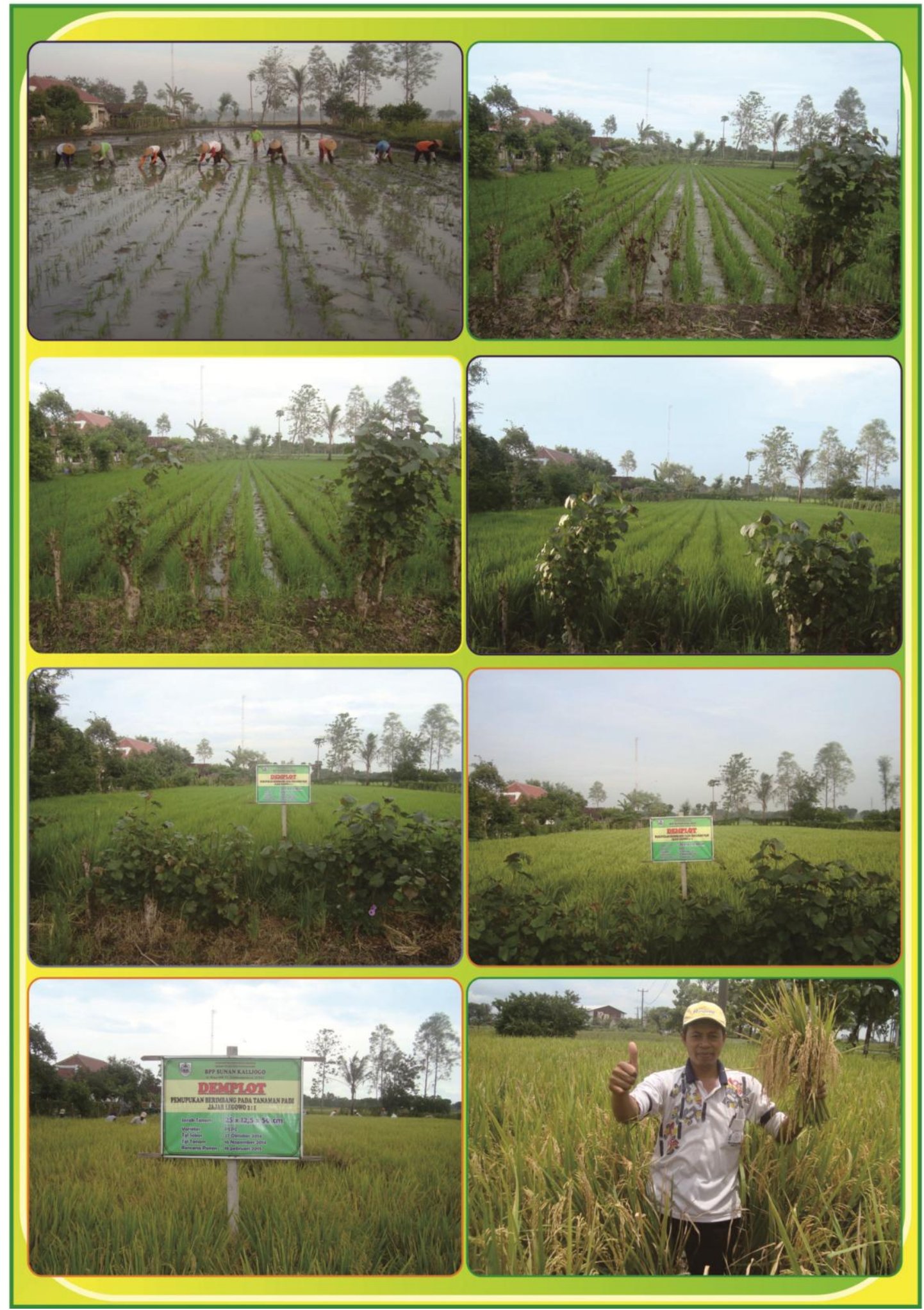




\section{HASIL PENGAMATAN DEMPLOT}

A LAPORAN AWAL TANAM

1 Musim Tanam : MT I 2015/2016

2 Nama Pelaksana : WIDODO

3 Alamat

Persemaian

7 Pengolahan Lahan

2 Nopember 2015

Dukuh : SUMBERAGUNG RT

8 Tanam

14 Nopember 2015

Desa : BANARAN

Kecamatan : Sambungmacan

Kabupaten : Sragen

4 Luas Lahan

9 Rencana Panen

19 Pebruari 2016

5 Varietas

$1000 \mathrm{~m} 2$

10 Dengan Jajar Legowo : 2:

$(20 \times 10 \times 40 \mathrm{~cm})$

\section{B LAPORAN PERKEMBANGAN}

1 Aplikasi Pupuk

Pemupukan 1 : 28 Nopember 2015

Jenis Pupuk

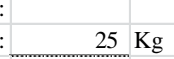

CIHERANG

$\begin{aligned} \text { ZA : } & \mathrm{Kg} \\ \text { SP 36 : } & -\mathrm{Kg} \\ \text { NPK PHONSKA : } & 25 \mathrm{Kg} \\ \text { Organik : } & 80 \mathrm{Kg} \\ \text { Lain - lain : } & -\mathrm{Kg} \\ & \mathrm{Kg}\end{aligned}$

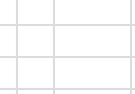

\begin{tabular}{|l|l|}
\hline & Pemupukan \\
\hline
\end{tabular}
$\mathrm{Kg}$

$\mathrm{Kg}$

$\mathrm{Kg}$

$\mathrm{Kg}$

\section{nis Pupuk}

UREA

SP 36

NPK PHONSKA :

PETROGANIK :

Lain - lain
11 Desember 2015

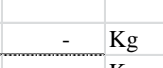

$\underline{2}$ Perkembangan Tanaman

Pengamatan Rata-rata Jumlah Anakan

Minggu 1

Minggu 2: 2 Anakan

Minggu 3

5 Anakan

Minggu 4

11 Anakan

14 Anakan

3 Pengendalian Organisme Pengganggu Tanaman (OPT)

Semprot 1 : Tanaman umur 35 HST

Pestisida yg dipakai Insektisida Joker

Fungisida Kontafplus

Semprot 2

Tanaman umur 45 HST

Pestisida yg dipakai Insektisida Joker, Abacel Fungisida Kontafplus

Semprot 3

Pestisida yg dipakai

Semprot 4

Pestisida yg dipakai
Pengamatan

Minggu 5

Minggu 6

Minggu 7 :

Minggu 8
Rata-Rata Jumlah Anakan 14 Anakan

14 Anakan

14 Anakan

14 Anakan

\begin{tabular}{|l|l|l|l|}
\hline & Fungisida Kontafplus & & \\
\hline & & \\
\hline
\end{tabular}

\section{LAPORAN AKHIR}

$\underline{1}$ Hasil Panen dengan sistem Ubinan $2,5 \times 2,5 \mathrm{~m}$

Di Petak Demplot : $\quad 5,6 \mathrm{Kg} \quad$ : $\quad 89,6$ Kwintal per ha Di Petak Kontrol : $\quad 4,5 \mathrm{Kg} \quad: \quad 72,0$ Kwintal per ha

2 Jumlah Anakan

Di Petak Demplot :

Anakan Produktif :

11 Anakan

Anakan tidak produktif : $\quad 2$ Anakan

Jumlah 13 Anakan

Di Luar Petak Demplot :

Anakan Produkt :

9 Anakan

Anakan tidak produkti :

Jumlah

2 Anakan

3 Jumlah Bulir Gabah per malai

Di Petak Demplot :

Gabah Bernas :

Gabah Hijau :

164 Bulir

Gabah Hampa

3 Bulir

Jumlah 169 Bulir

2 Bulir

Jumlah Bulir Gabah per malai

Di Luar Petak Demplot :

Insektisid Joker

Fungisida Kontafplus

Gabah Bernas :

Gabah Hijau :

Gabah Hampa :

Jumlah

D CATATAN PENTING

1 Di Petak Demplot Jumlah Anakan lebih tinggi dibanding diluar demplot

2 Di Petak Demplot Jumlah Anakan Produktif lebih tinggi dibanding diluar demplot

3 Di Petak Demplot Jumlah Bulir Gabah lebih tinggi dibanding diluar demplot

Sambungmacan, 19 Pebruari 2016

Pembuat Laporan

WIDODO, STP

THL TB PP Tahun 2007 


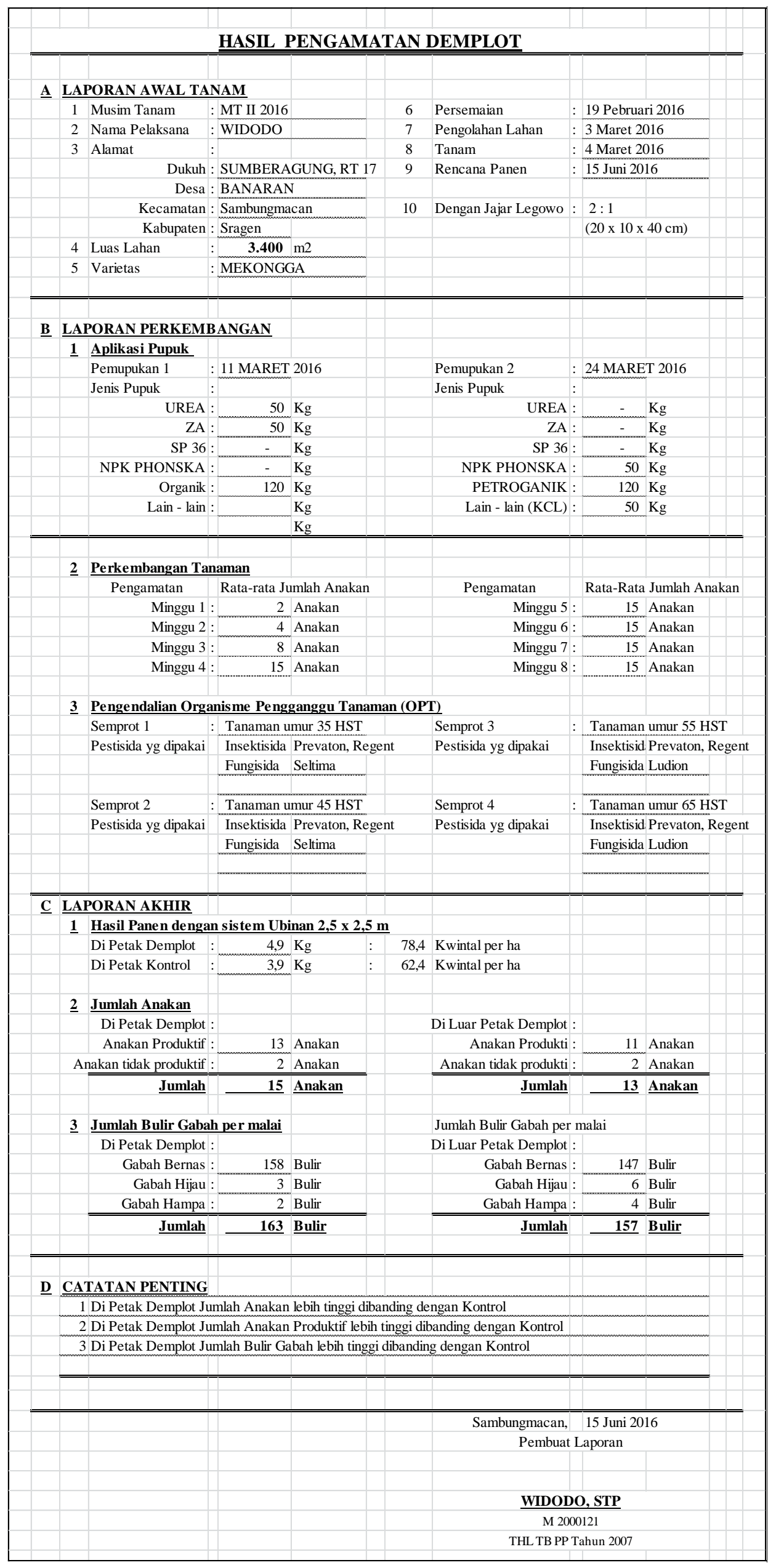




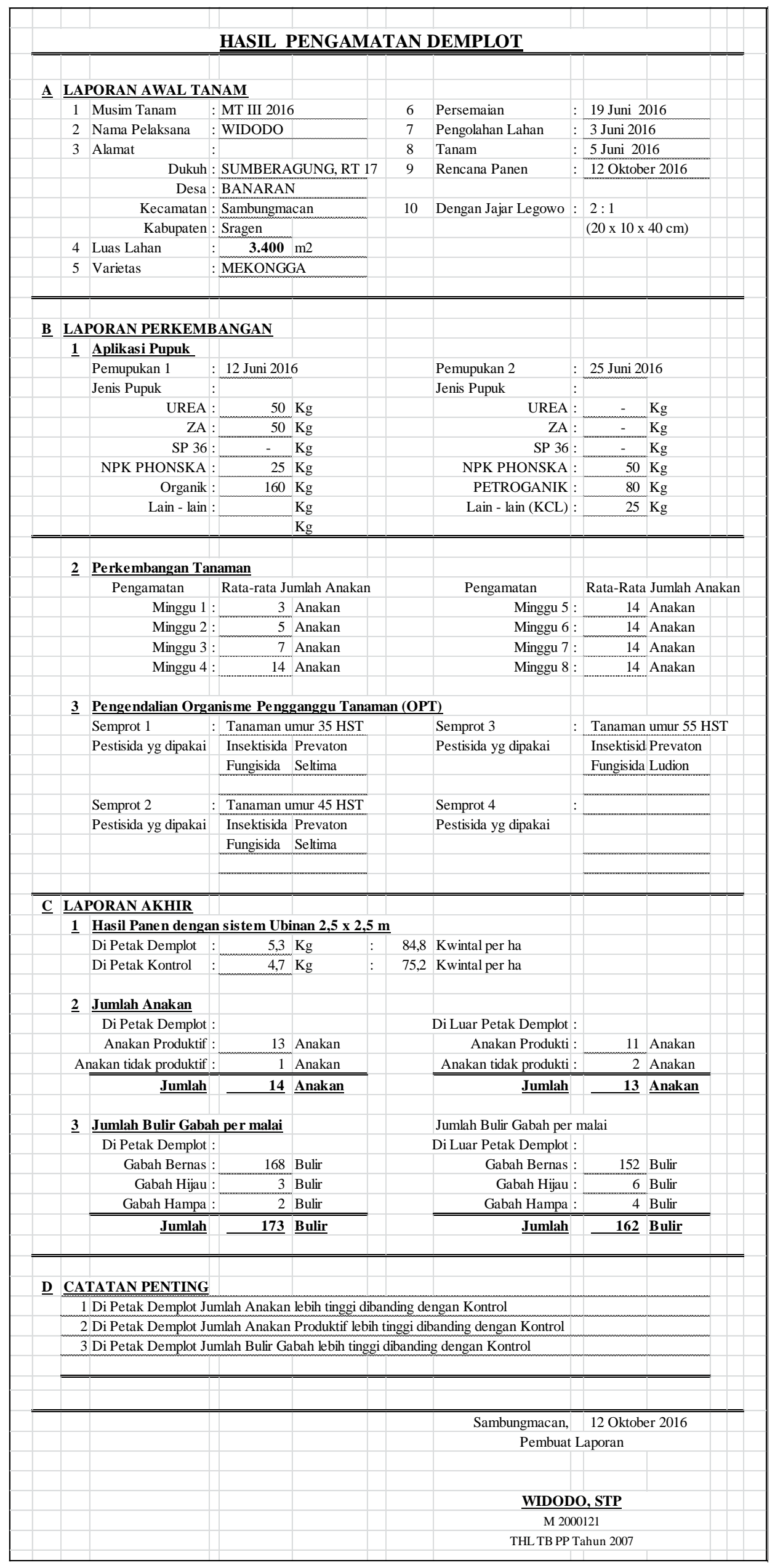




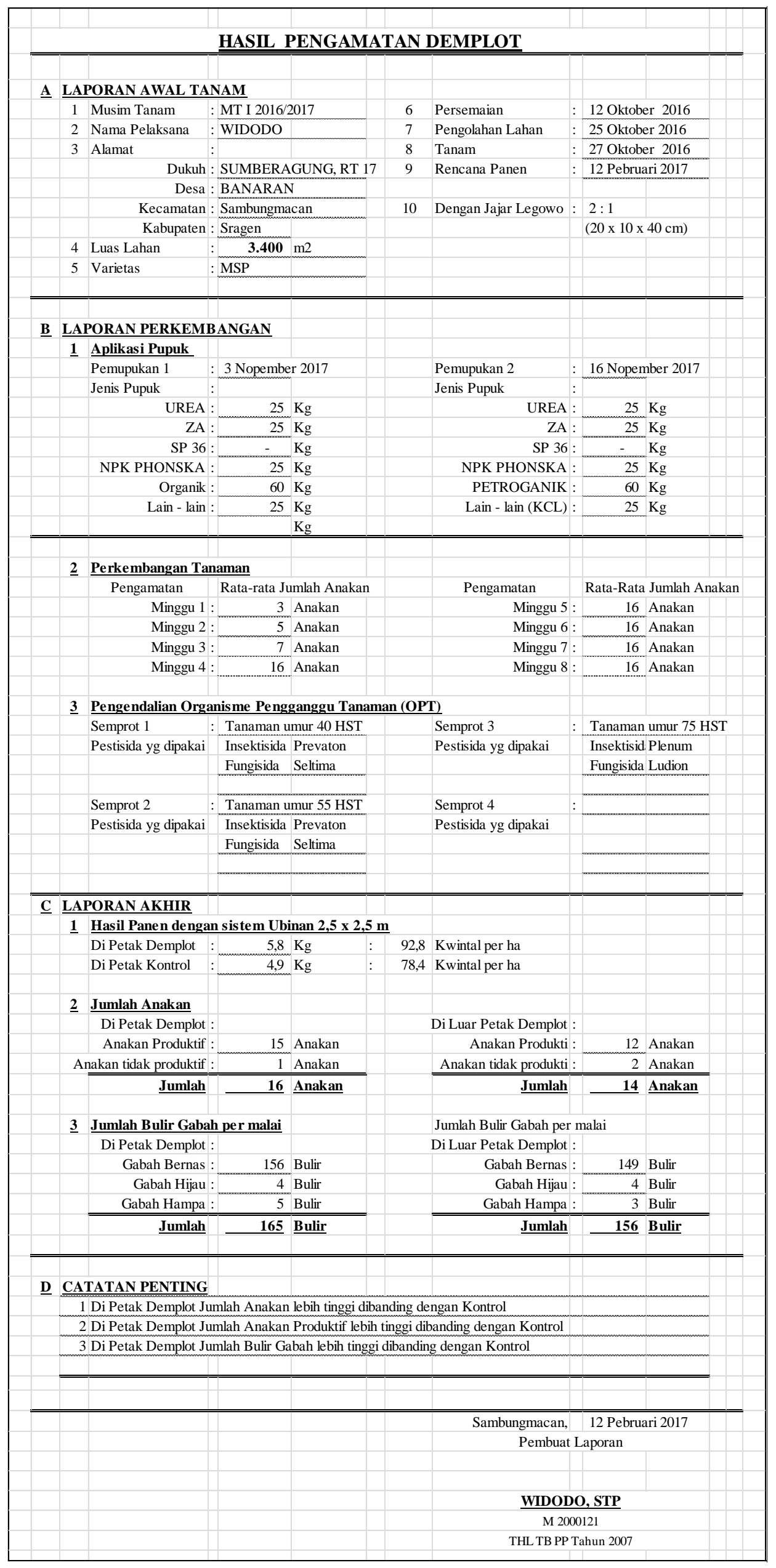




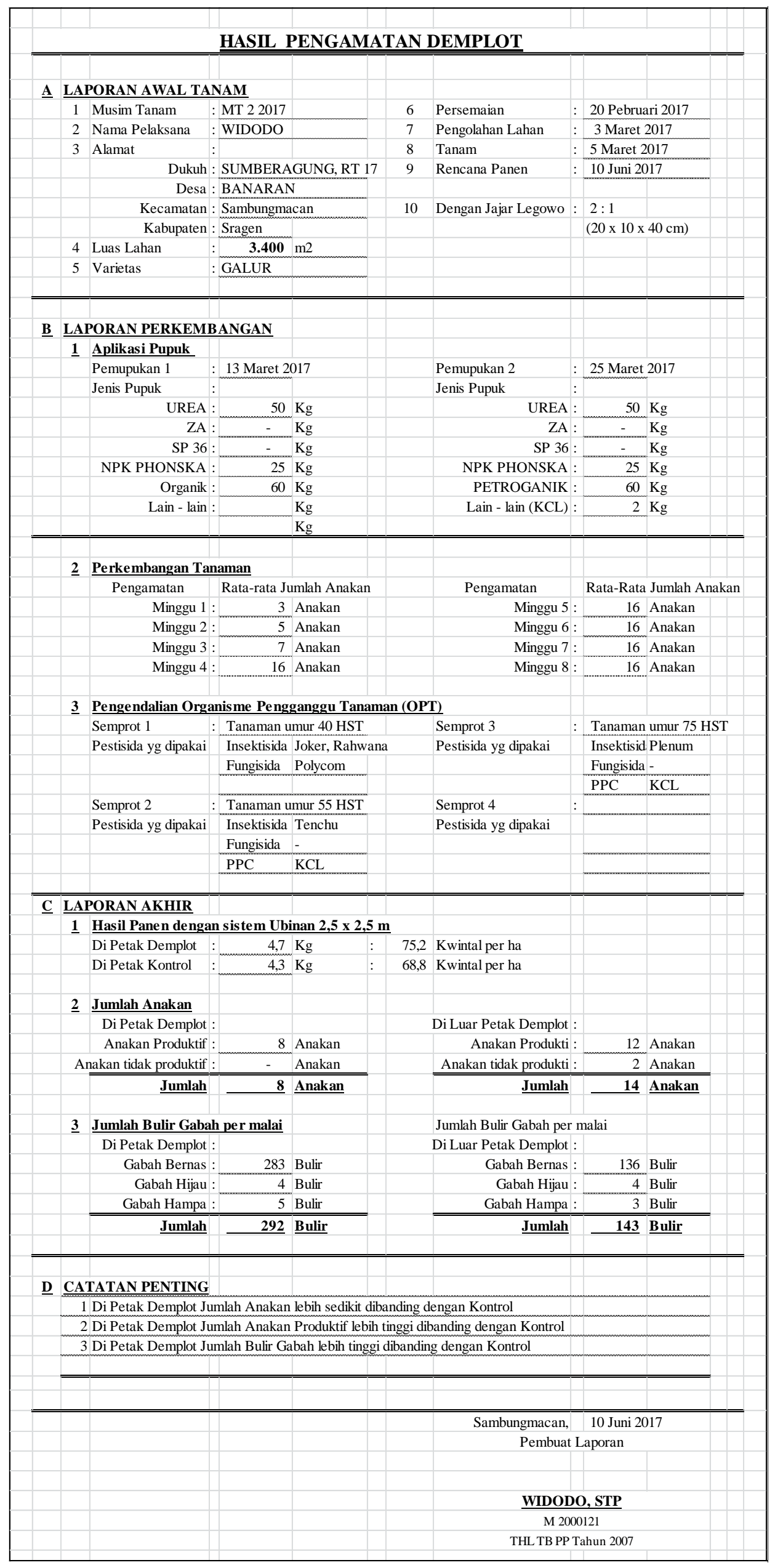


Sehubungan dengan hal tersebut diatas maka Kementerian Pertanian melaksanakan berbagai kegiatan untuk mempercepat pencapaian swasembada beras dalam 2 tahun kedepan dengan target. Untuk mendukung program tersebut salah satu kegiatannya adalah melakukan Demplot dalam bentuk atau demplot dilokasi sentra produksi di masing-masing balai penyuluhan pertanian sebagai salah satu metode penyuluhan yang dilaksanakan oleh petani dan dibimbing oleh penyuluh wilayah binaan. Adapun dari hasil Demplot ini dapat menjadi salah satu cara agar para petani yang berada disekitarnya dapat mengakses teknologi yang diterapkan dalam rangka meningkatkan produksi mereka. 